\title{
Corynebacterium atypicum sp. nov., from a human clinical source, does not contain corynomycolic acids
}

\author{
Val Hall, ${ }^{1}$ Matthew D. Collins, ${ }^{2}$ Roger A. Hutson, ${ }^{2}$ Paul A. Lawson, ${ }^{2}$ \\ Enevold Falsen ${ }^{3}$ and Brian I. Duerden ${ }^{1}$ \\ ${ }^{1}$ Anaerobe Reference Unit, PHLS, University Hospital of Wales, Cardiff CF14 4XW, UK \\ ${ }^{2}$ School of Food Biosciences, University of Reading, Reading, UK \\ ${ }^{3}$ Culture Collection, Department of Clinical Bacteriology, University of Göteborg, Göteborg, \\ Sweden
}

Correspondence

Val Hall

hallv@cardiff.ac.uk

\begin{abstract}
An unusual Gram-positive, facultatively anaerobic, catalase-positive, diphtheroid-shaped organism originating from an unknown human clinical source was characterized by biochemical, molecular chemical and molecular phylogenetic methods. Based on its morphological and biochemical characteristics and the presence of a murein based on meso-diaminopimelic acid, the unidentified organism was tentatively assigned to the genus Corynebacterium. However, the unknown organism was found to lack the distinctive, short-chain corynomycolic acids that are considered to be characteristic of this genus. Despite the absence of these characteristic lipids, comparative 16S rRNA gene sequencing showed that the unknown bacterium was phylogenetically a member of the genus Corynebacterium and was distinct from all currently known species. Based on both phenotypic and 16S rRNA sequence considerations, it is proposed that the unknown organism be classified as a novel species, Corynebacterium atypicum sp. nov. The type strain of C. atypicum is strain R2070 $\left(=\right.$ CCUG $45804^{\top}=$ CIP $107431^{\top}$ ).
\end{abstract}

Amongst the coryneform group of bacteria, the genus Corynebacterium comprises the largest number of species. The genus currently contains over 50 species, a high proportion of which have been defined during the past decade. Most of the newly described species have originated from clinical specimens, where they occur as cutaneous or mucocutaneous contaminants, and have come to light as a result of increased interest in the possible role of such organisms as opportunistic pathogens and due to the implementation of improved molecular diagnostic methodologies (Funke et al., 1997). Despite the rapid expansion in the number of corynebacterial species, there is strong evidence that much species diversity remains to be defined, especially from human sources (Tanner et al., 1999). The genus Corynebacterium forms a monophyletic grouping (Pascual et al., 1995), and species of this genus, with few exceptions (Corynebacterium amycolatum Collins et al. 1988 and Corynebacterium kroppenstedtii Collins et al. 1998), are characterized by the presence of distinctive low-molecularmass $\alpha$-alkyl- $\beta$-hydroxy long-chain fatty acids (designated corynomycolic acids) (Collins \& Cummins, 1986). In the course of an on-going study of taxonomically problematic coryneforms from human sources, we have characterized a

The GenBank/EMBL/DDBJ accession number for the $16 \mathrm{~S}$ rRNA gene sequence of strain CCUG $45804^{\top}$ is AJ441057. hitherto-unknown corynebacterium-like organism that lacks corynomycolic acids. Based on both phenotypic and phylogenetic evidence, we propose yet another novel species of the genus Corynebacterium, Corynebacterium atypicum sp. nov.

Strain R2070 ${ }^{\mathrm{T}}$ was submitted to the Anaerobe Reference Unit, PHLS, University Hospital of Wales, Cardiff, UK, for identification and originated from an unknown human clinical source. The unidentified rod-shaped isolate was cultured on Columbia agar (Difco) supplemented with $5 \%$ horse blood at $37^{\circ} \mathrm{C}$, in air plus $5 \% \mathrm{CO}_{2}$. The strain was characterized biochemically by using the API Coryne and API ZYM systems according to the manufacturer's instructions (API bioMérieux). Cell-wall murein was prepared by mechanical disruption of cells and complete acid hydrolysates were analysed as described by Schleifer \& Kandler (1972). Fatty acid methyl esters were prepared and analysed as described by Kämpfer \& Kroppenstedt (1996) and the presence of mycolic acids was investigated by GLC analysis of trimethylsilylated derivatives (TMS-MAME) (Klatte et al., 1994). The 16S rRNA gene of the isolate was amplified by PCR and sequenced directly using a Taq dye-deoxy terminator cycle sequencing kit (Applied Biosystems) and an automatic DNA sequencer (model 373A; Applied Biosystems). The closest known relatives of the novel isolate 
were determined by performing database searches. These sequences and those of other known related strains were retrieved from the GenBank or Ribosomal Database Project libraries and aligned with the newly determined sequence using the program DNATools (Rasmussen, 1995). The resulting multiple sequence alignment was corrected manually and a distance matrix was calculated using the programs PRETTY and DNADIST (using the Kimura-2 correction parameter) (Felsenstein, 1989). A phylogenetic tree was constructed according to the neighbour-joining method with the program NEIGHBOR (Felsenstein, 1989). The stability of the groupings was estimated by bootstrap analysis (500 replications) using the programs DNABOOT, DNADIST, NEIGHBOR and CONSENSE (Felsenstein, 1989).

The unidentified isolate consisted of Gram-positive, pleomorphic rods, ranging from short to medium-length cells in pairs joined end-to-end or chains to filamentous curved cells with thickened ends. The organism was non-acid-fast and non-spore-forming. The strain grew under aerobic and anaerobic conditions and was catalase-positive. Colonies on Columbia agar with $5 \%$ horse blood, after aerobic or anaerobic incubation at $37^{\circ} \mathrm{C}$ for $48 \mathrm{~h}$, were pinpoint, convex, entire-edged, shiny, white and non-haemolytic. It was non-lipophilic, did not reduce nitrate and did not hydrolyse aesculin, gelatin or starch. Using the API Coryne system, the unidentified organism produced acid from D-glucose, maltose, ribose and sucrose but not from glycogen, lactose, mannitol or D-xylose. It gave a positive reaction for $\beta$-glucuronidase but all other tests in the API Coryne system were negative. Using the API ZYM system, activity was detected for $\beta$-glucuronidase, cystine arylamidase, leucine arylamidase and valine arylamidase. All other enzyme tests using the API ZYM kit were negative. Based on its cellular morphology and biochemical reactions, the isolate somewhat resembled members of the genus Corynebacterium but it did not correspond to any recognized species.

An examination of the cell-wall murein of the unknown organism revealed the presence of meso-diaminopimelic acid, which was consistent with its provisional assignment to the genus Corynebacterium. The long-chain cellular fatty acids of the isolate consisted of C14:0 (2\%), C16:0 (27\%), $\mathrm{C} 18: 0(22 \%), \mathrm{C} 18: 1 \omega 9 c(39 \%)$ and $\mathrm{C} 18: 1 \omega 6 c(10 \%)$, which again resembled the properties of corynebacteria. Tuberculostearic acid was not present. TLC and GLC analysis revealed that corynomycolic acids were absent (or, if present, were in exceedingly small amounts compared with other corynebacterial species). The absence of mycolic acids is at variance with the vast majority of species of the genus Corynebacterium.

To ascertain the phylogenetic position of the unknown organism, its almost complete 16S rRNA gene sequence was determined. Sequence database searches confirmed that the unknown bacterium was most closely related to species of the genus Corynebacterium (data not shown). Treeing analysis demonstrated the placement of the unidentified bacterium within the genus Corynebacterium, with the novel organism forming a distinct subline. The unknown organism formed a loose association with Corynebacterium mastitidis, but bootstrap resampling showed that this affinity was not statistically significant. A tree based on a subset of Corynebacterium species, showing the nearest phylogenetic relatives of the novel bacterium, is shown in Fig. 1.

The unidentified diphtheroid from an unknown human source was found to represent a novel species of the genus Corynebacterium. The absence of corynomycolic acids in the unidentified Corynebacterium was unexpected, as only two species of the genus are known at present that lack these characteristic lipids, C. amycolatum (encountered on human skin and in clinical specimens) and C. kroppenstedtii (isolated from human sputum) (Collins et al., 1988, 1998). Phylogenetically, the unidentified organism clustered well within the confines of the genus Corynebacterium and formed a distinct subline, exhibiting a loose, albeit statistically non-significant, association with $C$. mastitidis and C. kroppenstedtii. Respective sequence divergence values of 6.3 and $7 \%$ from the aforementioned species clearly demonstrated that the unidentified diphtheroid represents a distinct species. Phenotypically, the novel rod can be readily distinguished from these corynebacterial species. The unknown organism differs from C. mastitidis in lacking mycolic acids, forming acid from glucose, maltose, ribose and sucrose and producing $\beta$-glucuronidase, $C$. mastitidis showing the opposite responses (Fernandez-Garayzabal et al., 1997). Although the unknown diphtheroid resembles C. kroppenstedtii in lacking mycolic acids, it differs from the latter species in producing $\beta$-glucuronidase, failing to produce pyrazinamidase and by failing to hydrolyse

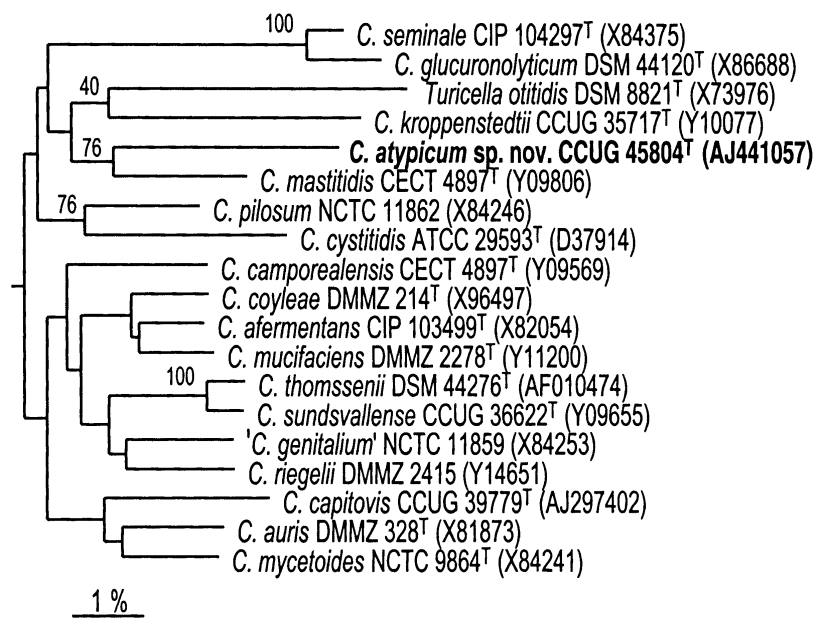

Fig. 1. Unrooted tree based on $16 \mathrm{~S}$ rDNA sequences and constructed using the neighbour-joining method showing the phylogenetic relationships of Corynebacterium atypicum $\mathrm{sp}$. nov. Bootstrap percentages (based on 500 replications) are given at branching points. Bar, $1 \%$ sequence divergence. 
aesculin. In addition, C. kroppenstedtii synthesizes tuberculostearic acid, whereas the unknown organism lacks this characteristic lipid (Collins et al., 1998). It is pertinent to note that the biochemical profile of the unknown organism, in concert with its failure to synthesize mycolic acids, serves to distinguish it from all currently recognized Corynebacterium species. Thus, based on phenotypic and phylogenetic evidence, we propose that the organism be classified as a novel species of the genus Corynebacterium, Corynebacterium atypicum sp. nov.

Although only a single strain of C. atypicum is currently known, given the rarity of amycolate corynebacteria, we consider that a formal taxonomic description is justified. In addition, the formal description of this species, together with biochemical and chemical criteria to aid its identification, will facilitate its recognition in clinical laboratories in future, thereby permitting the recovery of additional strains of this species and an evaluation of its distribution and clinical prevalence. Tests that are useful in distinguishing C. atypicum from its closest phylogenetic relatives and other amycolate corynebacteria are given in Table 1 .

\section{Description of Corynebacterium atypicum sp. nov.}

Corynebacterium atypicum (a.typ'i.cum. M.L. neut. adj. atypicum not typical, referring to the absence of corynomycolic acids, a feature normally present in corynebacteria).

Cells stain as Gram-positive, short to filamentous rods that

Table 1. Tests that are useful in distinguishing C. atypicum sp. nov. from its nearest phylogenetic relatives and other corynebacteria that lack mycolic acids

Species: 1, C. atypicum sp. nov.; 2, C. amycolatum; 3, Corynebacterium glucuronolyticum; 4, C. kroppenstedtii; 5, C. mastitidis. Biochemical tests were determined using the API Coryne system. TBSA, Tuberculostearic acid; v, variable.

\begin{tabular}{|lccccc|}
\hline Characteristic & $\mathbf{1}$ & $\mathbf{2}$ & $\mathbf{3}$ & $\mathbf{4}$ & $\mathbf{5}$ \\
\hline Acid from: & & & & & \\
$\quad$ Glucose & + & + & + & + & - \\
Maltose & + & $\mathrm{V}$ & + & + & - \\
Ribose & + & + & $\mathrm{V}$ & - & - \\
Sucrose & + & $\mathrm{V}$ & + & + & - \\
Production of: & & & & & \\
$\quad$ Alkaline phosphatase & - & + & - & $\mathrm{V}$ & + \\
$\quad \beta$-Glucuronidase & + & - & + & - & - \\
$\quad$ Pyrazinamidase & - & + & + & + & + \\
$\quad$ Urease & - & - & $\mathrm{V}$ & - & $\mathrm{V}$ \\
Hydrolysis of aesculin & - & - & $\mathrm{V}$ & + & - \\
Presence of: & & & & & \\
$\quad$ Mycolic acids & - & - & + & - & + \\
TBSA & - & - & - & + & - \\
\end{tabular}

are non-acid-fast, non-spore-forming and non-motile. Facultatively anaerobic and catalase-positive. Colonies on Columbia agar with $5 \%$ horse blood, after incubation at $37^{\circ} \mathrm{C}$ for $48 \mathrm{~h}$, are pinpoint, convex, entire-edged, shiny, white and non-haemolytic. Non-lipophilic. Growth occurs in broth containing $7 \cdot 5 \% \mathrm{NaCl}$ but not in $10 \% \mathrm{NaCl}$. Aesculin, gelatin and starch are not hydrolysed. Using API systems, acid is produced from D-glucose, maltose, ribose and sucrose. Acid is not produced from lactose, mannitol, glycogen or D-xylose. Activity is detected for $\beta$-glucuronidase, cystine arylamidase, leucine arylamidase and valine arylamidase. Alkaline phosphatase, acid phosphatase, chymotrypsin, esterase C-4, ester lipase C8, $\alpha$-fucosidase, $\alpha$-galactosidase, $\beta$-galactosidase, $\alpha$-glucosidase, $\beta$-glucosidase, lipase $\mathrm{C} 14, \alpha$-mannosidase, $N$-acetyl- $\beta$ glucosaminidase, phosphoamidase, pyrrolidonyl arylamidase, pyrazinamidase, trypsin and urease are not produced. Acetoin is not produced. Nitrate is not reduced to nitrite. The cell-wall murein contains meso-diaminopimelic acid. The long-chain cellular fatty acids are of the straight-chain saturated and monounsaturated types, with C16:0, C18:0 and $\mathrm{C} 18: 1 \omega 9 c$ predominating. Tuberculostearic acid is not present. Mycolic acids are not detected but, if present, are at very low levels.

The type strain, strain $\mathrm{R} 2070^{\mathrm{T}}$ (=CCUG $45804^{\mathrm{T}}=$ CIP $\left.107431^{\mathrm{T}}\right)$, was isolated from an unknown human clinical source. Habitat is not known.

\section{References}

Collins, M. D. \& Cummins, C. S. (1986). Genus Corynebacterium Lehmann and Neumann 1896, 350 $\mathrm{AL}$. In Bergey's Manual of Systematic Bacteriology, vol. 2, pp. 1266-1276. Edited by P. H. A. Sneath, N. S. Mair, M. E. Sharpe \& J. G. Holt. Baltimore: Williams \& Wilkins.

Collins, M. D., Burton, R. A. \& Jones, D. (1988). Corynebacterium amycolatum sp. nov., a new mycolic acid-less Corynebacterium species from human skin. FEMS Microbiol Lett 49, 349-352.

Collins, M. D., Falsen, E., Åkervall, E., Sjöden, B. \& Alvarez, A. (1998). Corynebacterium kroppenstedtii sp. nov., a novel corynebacterium that does not contain mycolic acids. Int J Syst Bacteriol 48, 1449-1454.

Felsenstein, J. (1989). PHYLIP - phylogeny inference package (version 3.2). Cladistics 5, 164-166.

Fernandez-Garayzabal, J. F., Collins, M. D., Hutson, R. A., Fernandez, E., Monasterio, R., Marco, J. \& Dominguez, L. (1997). Corynebacterium mastitidis sp. nov., isolated from milk of sheep with subclinical mastitis. Int J Syst Bacteriol 47, 1082-1085.

Funke, G., von Graevenitz, A., Clarridge, J. E., III \& Bernard, K. A. (1997). Clinical microbiology of coryneform bacteria. Clin Microbiol Rev 10, 125-159.

Kämpfer, P. \& Kroppenstedt, R. M. (1996). Numerical analysis of fatty acid patterns of coryneform bacteria and related taxa. Can J Microbiol 42, 989-1005.

Klatte, S., Kroppenstedt, R. M. \& Rainey, F. A. (1994). Rhodococcus opacus sp. nov., an unusual nutritionally versatile Rhodococcus species. Syst Appl Microbiol 17, 355-360. 
Pascual, C., Lawson, P. A., Farrow, J. A. E., Navarro Gimenez, M. \& Collins, M. D. (1995). Phylogenetic analysis of the genus Corynebacterium based on $16 \mathrm{~S}$ rRNA gene sequences. Int J Syst Bacteriol 45, 724-728.

Rasmussen, S. W. (1995). DNATools, a software package for DNA sequence analysis. Carlsberg Laboratory, Copenhagen.
Schleifer, K. H. \& Kandler, O. (1972). Peptidoglycan types of bacterial cell walls and their taxonomic implications. Bacteriol Rev 36, 407-477.

Tanner, M. A., Shoskes, D., Shahed, A. \& Pace, N. R. (1999). Prevalence of corynebacterial $16 \mathrm{~S}$ rRNA sequences in patients with bacterial and "nonbacterial" prostatitis. J Clin Microbiol 37, 1863-1870. 